Absorption of carbolic acid was suggested as the cause of the collapse, but I see no reason to regard that as probable, and the urine which was withdrawn was in no way abnormal. The disease had been slowly progressing for a fortnight before surgical interference. The patient suffered from pulmonary emphysema and was addicted to alcohol.

In a very large proportion of cases of cancrum oris pneumonia or noma, perhaps combined with gangrene of the anus, or pneumonia and noma together, appear as complications. Of 173 cases described in the American Journal of the Medical Sciences as occurring in a recent epidemic more than one-fifth had one or other complication or both combined. These complications may accentuate the constitutional effects or may introduce a further antagonist to the patient's power of resisting the disease, but from its position and its virulence and ravidity it must always prove exceedingly dangerous to the life of the individual attacked. The patient is always one with a constitution debilitated by disease or habit of life. With this weakened organism we have the disease in a position where, though the nutrient supply of the tissues is abundant, there is also an abundant absorption. Toxalbumins and bacilli will rapidly pass into the blood, and it is reasonable to suppose that in many cases septic emboli and thrombosis may extend through the veins to the cavernous and other sinuses. In nine bacteriological examinations carried out during the American epidemic a leptothrix was found constantly present, but it is impossible to fulfil all the laws which are required to prove this to be the distinctive organism of the disease. Probably it is a mixed infection, for there are always numerous other bacilli and cocci present, and in one of my cases the colour of the pus was distinctly bluish-green, as it would be under the influence of the bacillus pyocyaneus.

Cardiff.

\section{A CASE ILLUSTRATING THE EFFECTS OF PRESSURE ON EARLY SYPHILITIC WARTY GROWTHS.}

By Arthur Shillitoe, M.B. Cantab., F.R.C.S. Eng.,

SURGEON TO OUT-PATIENTS TO THE LONDON LOCK HOSPITAL.

AT the October meeting of the Dermatological Society of Great Britain and Ireland I showed a young man with papillomata and condylomata present at the same time on the tongue. He gave the following history. Gonorrhœa was acquired about Christmas, 1900, followed by a chancre on the penis in January, 1901. He was treated privately from January to July and had had no eruption on the body to his knowledge. In June last he had warts on the penis which were destroyed by caustics.

According to Mr. J. Hutchinson, sen., if warts should be found on the penis of a syphilitic subject, the tongue should always be examined for a like condition; and, if present (which they often are), they will be seen to be situated on the posterior third of the dorsum between the arms of the $V$ formed by the circumvallate papillæ- that is to say, on that part of the tongue which does not come in contact with the palate and therefore is not subjected to pressure. While agreeing with this-viz., the formation of papillomata on a part not subject to pressure-one cannot but remember how often in venereal patients (both gonorrhœal and syphilitic) are seen large masses of warts beneath a tight or phimosed prepuce where the pressure must be fairly constant and considerable. On examining my patient I found that he certainly had a few small warts about the corona and on looking at his tongue there were seen several papillomatous growths in the position above indicated. In addition, scattered over the anterior two-thirds of the dorsum and the margins of the organ were eight or 10 large, flat-topped, white condylomata, with sharply defined margins - that is to say, on that part of the tongue which is subject to the intermittent pressure of the palate and teeth. When we consider the positions of condylomata in other parts we find that they, too, occur in situations subject to intermittent pressure-e.g., the natal fold, the inner aspect of the thighs, and the sides of the scrotum.

It seems to me that (1) pressure, as seen in the case of a phimosed prepuce, and (2) no pressure at all, as in the posterior third of the dorsum of the tongue, exert an equal influence in determining the formation of ordinary-looking papillomata; whereas, if the pressure be intermittent, as seen in the anterior two-thirds of the tongue, the inner aspect of the thighs, and the sides of the scrotum, or in the natal fold, then these papillary hypertrophies assume a condylomatous form.

In conclusion, my patient told me that his tongue was in much the same condition last July and that it yielded so rapidly to treatment that he took no further medicine, until I saw him at the hospital early in October, when the lesions speedily disappeared under mercury.

For permission to publish the above case I am indebted to the Dermatolngical Snciety of Great Britain and Ireland.

Frederick-place, E.C.

\section{NOTE ON A CASE OF CONGENITAL ATROPHY OF THE RIGHT KIDNEY.}

By R. Niven, M.B , Ch.B. GlasG.

ASSISTANT MEDICAL OFFICIR, BETHNALL HOLSE ASYLUM, LONDON, K.E.

A man, aged 57 years, died at Bethnall House Asylum on Nov. 9th, 1901, from asthenia consequent on general paralysis of the insane, complicated by hypostatic engorge. ment of the lungs. At the necropsy no trace of the right kidney could at first be discovered. On removing the right suprarenal capsule, however, a small reddish mass of about the size of a scarlet-runner bean was discovered embedded in the surrounding areolar tissue and close to the lower margin of that organ. The connexions with vessels and ureter were thus unfortunately severed before a careful dissection was made. A small vessel, probably a vein, was found emerging from the inner border of the reddish body. A very small artery, probably the right renal, came off the abdominal aorta opposite to, and on a level with, the left renal artery. On dissection, a fine tube was found following: the normal course of the ureter and was traced downwards to the bladder which it entered at a point on the right side of that organ corresponding to the point of entry of the left ureter on the other side. A stout hairpin was with difficulty passed through a small surface at the right posterior angle of the trigonum vesicæ, and it travelled along the tube for about two inches. On microscopical examination the reddish mass embedded in fat had the structure of very atrophied kidney substance. A few tubules were seen to be scattered through an abundance of dense fibrous tissue. They were lined with flattened epithelium and were filled with retained secretion. The vessels in the dense fibrous stroma were very thickwalled. The right kidney exhibited some degree of compensatory hypertrophy. Its position and relations were normal. The organ weighed seven ounces, it was of healthy colour and apparently normal on section, and the capsule stripped easily. Microscopical examination showed the kidney to be practically healthy. There were small patches of fibrous tissue here and there, but the glomeruli were not degenerated and the convoluted tubules were not dilated. The urine was neither measured nor examined during life, as the man was during the period of his residence here indifferent to the calls of nature and passed urine and fæces under him. Throughout life there were no symptoms indicating defect in the urinary organs.

For permi-sion to publish this case I am indebted to the kindness of Dr. J. Kennedy Will, medical superintendent of the Bethnall House Asylum.

Cambridge-road, N.E.

\section{A NOTE ON A CASE OF PURPURA.}

By T. Edward Sandali, M.B., B.C. Cantab.

A WELL-MARKED case of purpura is perhaps sufficiently rarely met with in general practice as to warrant a brief report. The following case is of interest on account of the peculiarity and duration of the premonitory symptoms which completely puzzled me at the time, and until I saw the characteristic eruption on the ninth day of the illness $I$ had no idea that I was dealing with a simple case of purpura.

The patient was a girl, aged 15 years, who had always enjoyed good health but had not yet menstruated. I first saw her on Nov. 11th, 1901, when she complained of acute pain in the calf of the leg and in the popliteal space on both sides which, having begun the day before, became so acute that she was quite unable to walk and she had to crawl upstairs to bed on her hands and knees. There was no other symptom; the temperature was normal, the appetite was good, 